\title{
Just Ordinary Water - A Necessity for All Forms of Life
}

\author{
Ingrid Fredriksson
}

Copyright $\odot 2016$ by authors, all rights reserved. Authors agree that this article remains permanently open access under the terms of the Creative Commons Attribution License 4.0 International License

\begin{abstract}
In every living being and organism there is an entire world as amazing as the one we see around us. In our body there are 100 trillion cells $\left(10^{12}\right)$, and DNA that extends 10,000 kilometers. The base pairs in our DNA are held together by hydrogen. Maybe the hydrogen bonds in DNA's base pairs that constitutes our immune system and our consciousness. There is water in the cells, and between them, and while large molecules have to go through membrane proteins to enter the cells, small molecules like $\mathrm{H}_{2} \mathrm{O}$ and $\mathrm{O}_{2}$ can pass through the cell membrane without difficulty. In the spaces between the brain cells, at the end of every neuron, the basic unit of a brain cell is synapses, where chemical charges build up. In the same space dendrites - tiny filaments of nerve endings communicate with other neurons, sending out and receiving their own electrical wave impulses. This, together with the quantum hologram and non-local consciousness, provides an explanation and an exciting developmental phase in the illusion in which we live.
\end{abstract}

Keywords Consciousness, Electrons, Water, Micro and Macro

\section{Introduction}

'It all depends on water,' said the Italian researcher Giuseppe Vitiello, whom I met first at a conference on Quantum Mind in Salzburg, Austria, in the summer of 2007 and later on at several similar conferences. And the issue, of course, had to do with our brain and our consciousness.

Vitiello keeps talking of a strange 'time-reversed mirror' mode in the environment that pairs off as a non-locally quantum-connected Einstein-Rosen-Podolsky (EPR) twin or doppelganger to a Dipole Wave Quantum (DWQ). These DWQ are provided by the molecular electrical dipoles of biomolecules and the water matrix in which they are embedded. In other words, Vitiello has a non-locally correlated pair of quanta, one in the dipole wave and its time-reversed twin in the 'environment'. He claims that this non-local quantum connection or entanglement between the two quanta, one in the Fröhlich wave and the other in the external environment, 'can be seen as a self-interaction term' of the Fröhlich mode in which the environmental twin is part of the 'self-recognition' process.

Vitiello has a detailed mathematical model of dissipative damped quantum oscillators, in which the coupling to the environment undergoes the 'superconducting' [1].

That might not be so easy to understand, but it was for this reason that I have been involved with the significance of water for consciousness.

Perhaps our thoughts consist of electromagnetic wave motions, energy we emit when we think. Nobel Laureate Luc Montagnier told Science in discussing phenomen of electromagnetic waves produced by DNA in water.

'What we have found is that DNA produces structural changes in water, which persist at very high dilutions, and which lead to resonant electromagnetic signals that we can measure. Not all DNA produces signals that we can detect with our device. The high-intensity signals come from bacterial and viral DNA.

I have found these signals coming from bacterial DNA in the plasma of many patients with autism, and also in most, if not all, patients with Alzheimer, Parkinson's disease, and multiple sclerosis.

It seems that the bacteria we are detecting are coming from the gut. So it is quite possible that products from gut bacteria end up in the plasma and cause damage to the brain [2]'.

The base pairs in our DNA are held together by hydrogen. Essential water, the precondition for all life! I recall how, at a Toward a Science of Consciousness conference, I asked Nobel laureate Luc Montagnier and Giuseppe Vitiello if it could be said, a bit simplified, that our entire immune system was dependent on water. The answer was yes. [3].And that is how it is, then (Vitiello 2001).

The hypothesis: Consciousness might be found in the hydrogen bonds of DNA base pairs that constitute our immune system and our consciousness. The hypothesis is not tested, more experiments are necessary to prove the hypothesis.

\section{What Exactly Is Water?}


Water is everywhere around us. The human body is made of 70 percent water. Water is a chemical union between hydrogen and oxygen. The atoms are attached to each other in an asymmetrical fashion which means that one end has a surplus of positive electrical energy while the other has a surplus of negative electrical energy. Water, then, is a dipole. Water molecules have a tendency to adhere firmly to each other so that a positive end attracts a negative end and vice versa. This is called hydrogen bonding and is the basis of water's totally unique characteristics.

Its outstanding solvent capacity has already been mentioned, and it has other remarkable properties as well.

It's peculiar density ratio. Water is heaviest at $4^{\circ} \mathrm{C}$, not at $0^{\circ} \mathrm{C}$, the freezing point. The density of a substance depends on how tightly atoms and molecules are packed. Ordinarily, a solid substance has greater density than the same substance in liquid form. Water is an exception: ice has a lower density than water. It is due to the more spacious construction of ice that ice floats on water. If water were heaviest at $0^{\circ} \mathrm{C}$, the ice would form at the bottom of lakes and rivers, freezing from the bottom up; the fish would die and the ice would never have time to melt in the spring. The question is whether life would have been able to arise on earth at all if that had been the case.

It's great ability to store heat. In hot weather, the water in oceans and big lakes absorbs heat, which it radiates when the air is cold. This tempers the climate.

It's high surface tension and capillary action. Surface tension makes it possible for objects to be carried by the hydrogen bonds on the surface of water, even if the material is heavier than water. This gives insects the possibility to stand on water, and all of us have probably seen mosquito larvae in a puddle of water. Capillary force means that water can climb upwards in fine tubes despite the power of gravity. Thanks to capillary force a tree is able to 'lift' water high up into its foliage.

Water is not just $\mathrm{H}_{2} \mathrm{O}$ molecules. It contains a number of molecular species including ortho and para water molecules, water molecules with different isotopic compositions such as $\mathrm{HDO}$ and $\mathrm{H}_{2}{ }^{18} \mathrm{O}$, such water molecules as part of weakly bound but partially-covalently linked molecular clusters containing one, two, three or four hydrogen bonds, and hydrogen ion and hydroxide ion species. Apart from such molecules there are always adventitious and self-created solutes in liquid water. Distilled and de-ionized water contain significant and varying quantities of contaminating ions. Often the criterion for "purity" is the conductivity, but this will not show ionic contaminants at nano-molar, or even somewhat higher, concentrations due to the relatively high conductivity of the $\mathrm{H}+$ and $\mathrm{OH}$ - naturally present [4].

\section{Water and Our Genetic Code}

Water is able to dissolve the majority of chemical elements and carry them with it. Iron, calcium, and nitrogen compounds are but a few examples of the substances that can be dissolved in water. Chemically pure water does not exist in nature, and water's solvent capacity is a precondition for life itself. The water that rises in plants conveys dissolved nutrients to all parts of the plant. The human body is likewise sustained by nutrients that have been dissolved in the water of the blood.

How is it, then, with oils and non-polarized substances, which are not water soluble? It is this very circumstance the fact that some substances seem to love spending their time in water while others abhor it - which is the key to how water helps life's most important building blocks genes and proteins - achieve the specific, three-dimensional shapes that determine the function of the large bio-molecules. When proteins react with one another or with the genes it is crucial, of course, that the molecules fit one another.

Newly constructed proteins emerge from the cell's protein factories like a long necklace whose beads are amino acids, and only in the cellular fluid does the protein fold itself up into its compact three-dimensional form. Some of the amino acids are water-shunning, and these are folded naturally into the centre of the proteins, where they avoid all contact with water, while other amino acids are water-loving, and these end up on the outside of the protein instead. In the middle of the 1980's, Robert J. Lefkowits and Brian K. Kobilka managed to find the gene that encrypts for the benefit of the adrenaline receptor, the molecule to which the adrenaline hormone actually attaches itself.

The receptor consisted of seven long strings and their construction indicated that they were not fond of water, but instead preferred an environment rich in fat. The strings twisted back and forth through the cell wall seven times. Rhodopsin is another receptor that twists seven times. It is located in the retina of the eye and catches light. Similar receptors are located on the surface of the cell and they take care of the communication between what is outside of the cell and what is inside. Without these receptors we would not be able to see any light, smell any scents or experience any flavours. For this discovery Lefkowitz and Kobilka have been awarded the Nobel Prize in Chemistry 2012.

Computer simulations have shown that the double helix of DNA breaks apart if there is an attempt to model it without the presence of water. This is due to the fact that the water molecules create hydrogen bonds between the phosphate groups of the DNA strands, which would otherwise repel each other.

Water molecules can also be captured in water-loving pockets inside proteins. An experiment by biophysicists in Bochum, Germany, has shown how water plays a central role for the function of these proteins. Measurements of the protein bacteriorhodopsin provide one example. This protein is stored in the cell membrane of photosynthetic bacteria and handles the first step in the bacteria's photosynthesis. When the protein absorbs a light particle, it uses a network of water molecules in an interior channel to 
transfer a proton from the inside of the cell to the outside of the membrane, where a different protein snaps up the proton and puts energy into producing biological fuel. The researchers established that the process is possible only because the hydrogen bonds in water are formed and broken very easily.

New research indicates that water participates actively in the communication between genes and proteins. Without this interaction, life as we know it would simply be inconceivable [5].

Our body as a whole consists of at least two-thirds water - and the brain is 80 per cent water. As the brain tissue converts glucose from the blood into oxygen and energy, which are consumed in the brain cells' communication, it produces water. A human brain contains about one litre of water and produces fifty millilitres of water every twenty-four hours. Our body contains the most water in the foetal stage and somewhat less when we are children. As we age, the water content of our body decreases.

\section{The Water Crystal}

We know that no two snowflakes are alike. When water freezes, ice crystals are formed. Masaru Emoto (1943 2014) [6]. was a Japanese businessman who has become known as a researcher into water's inner forces and is most known for his photographs of water crystals. He has developed a method of photographing water during deep-freezing in a standardized manner, so that separate water tests can be compared. No one else, however, has replicated his work with photographing ice crystals; as a result, it cannot be evaluated from a scientific standpoint.

What makes Emoto's work a bit controversial is that he ascribes to water the ability to hear and to read [6]. If the label on the water bottle says 'fool', for example, there will be a totally different crystal image than when it says 'truth and happiness'. Tap water also changed after a prayer, and after 'love and thanks' the water formed beautiful crystals. When the SARS epidemic was raging, Emoto showed the water the abbreviated term in both English and Japanese, but there was not much difference between them and the crystals that are normally found in ordinary distilled water. When the whole name, Severe Acute Respiratory Syndrome, was written out there were no well-formed crystals in this water at all. Then the 'Severe Acute Respiratory Syndrome' labels were removed and replaced with 'love and thanks'. These words, according to Emoto, then created beautiful crystals, regardless of language.

For Emoto, this bears out his theories on water: water captures the vibrations of words and reflects them in the form of crystals. As long as a word is used in the right way, the water's reaction is the same, regardless of language.

It is good to be as concrete as possible, since the water is sensitive to vibrations. (This means, for example, writing 'Severe Acute Respiratory Syndrome' instead of the abbreviation 'SARS', so that the water can really take in the import of the words.)

The words 'love and thanks' have strong positive energy.

Even if the water's energy is damaged, it can be restored again.

The experiment was conducted by Dean Radin, Ph.D., who is the Chief Scientist at IONS and Adjunct Faculty in the Department of Psychology at Sonoma State University. The experiment was done to measure how intention alone affects water crystal formation. Co-Investigators were Masaru Emoto, along with a few other researchers and scientists.

The experiment tested the hypothesis that water exposed to distant intentions affects the aesthetic rating of ice crystals formed from that water. Basically, it tested whether intentions could influence the physical structure of water (as mentioned earlier). Over a period of three days, approximately 2000 people in Austria and Germany focused their intentions towards water samples that were placed inside an electromagnetically shielded room in California. Other samples were located outside of the shielded room so that they could act as a distant control. Ice drops formed from multiple samples of water in different treatment conditions were photographed by a technician. Each image was assessed for aesthetic beauty by over 2,500 independent judges and the results of the data were analyzed by individuals who were blind with respect to the treatment conditions.

Results showed that the test was consistent with a number of previous studies suggesting that intention may be able to influence the structure of water [7].

What if Emoto was right that the water in our body is not only able to listen but also reads thoughts? What if it is the hydrogen bonds in DNA's base pairs that constitute our immune system and all our consciousness?

\section{Kaivarainen and Water}

The Finnish researcher Alex Kaivarainen is fully convinced of the significance of water. He is the author of 5 books and more than 110 scientific publications (e.g. 'New Hierarchic Theory of Water and Its Application to Analysis of Water Perturbations by Magnetic Field: Role of Water in Biosystems'). Kaivarainen has developed theories on bivacuum, duality, electromagnetism, gravitation, and time. One of his computer programs deals with condensed matter like water and ice in the hierarchic theory. A great deal has to do with water's being a dipole.

A water molecule consists of one oxygen atom and two hydrogen atoms. The two hydrogen atoms stick out from the oxygen atom at a $105^{\circ}$ angle. The water molecule as a whole is not electrically charged, but it has two poles. The electrons which oxygen and hydrogen share are in lower periods around the oxygen atom than they are around the hydrogen atom. The two remaining electron pairs in the outer shell of the oxygen atom stick out from the oxygen atom like two electron clouds with a mildly negative charge. 
Conversely, there are two mildly positive charges around the two hydrogen atoms, which lack their electron. The mutual attraction between the positive and the negative charges in water molecules creates what are called hydrogen bonds. They function as handles between the water molecules, and in liquid water they are constantly being formed and broken. It is the hydrogen bonds that give water its unique characteristics. Water molecules prefer to have four bonds with other water molecules, and they therefore arrange themselves so that the surface where they turn one side out towards the air is as small as possible.

The water molecule looks like a fat little figure whose body corresponds to the oxygen atom. The figure has two outstretched arms corresponding to the electron clouds around the oxygen atom and two outstretched legs corresponding to the two hydrogen atoms. When several water molecules are gathered, each water molecule tries to take hold of four other water molecules. The negatively charged arms catch their neighbours' positively charged legs, and vice versa.

Water becomes more difficult to describe the lower the temperature gets, since more and more phenomena and structures are able to occur then. There are eighteen different crystal forms, for example, and complicated links between the electrons in the water molecules. [8]

\section{Electromagnetism}

An extraordinary paper authored by Nobel prize-winning Luc Montagnier has described memory effects in aqueous DNA solutions that the authors propose depend on interactions with the background electromagnetic field. These effects, if real, require the prior processing and dilution of the solutions and are explained by Montagnier as resonance phenomena with nanostructures derived from the DNA and water[9] [10].

Jacques Benveniste proposed water memory in the $1980 \mathrm{~s}$, and famously managed to publish some of his results in the journal Nature [11]. Lacking any objective grounds to reject the seemingly impossible paper through the process of peer review (so the many claims that established science merely rejects quack ideas with a closed mind are patently false), the paper was sent to press. The journal's editor John Maddox, however, remained skeptical and allowed the results to be published accompanied by a small editorial on the subject by himself, stating in the piece the number of laws of physics and chemistry such a result would violate and that 'There are good and particular reasons why prudent people should, for the time being, suspend judgment [12].' The only other remaining condition was that the research mentioned was independently replicated following publication and the controversy created a small media storm in 1988. The team sent to investigate Benveniste's claims included James Randi - whose expertise on sleight of hand and fraud detection were put to use in the lab. The report from the team concluded that although Benveniste was innocent of academic misconduct and fraud, he had been misled by flawed experiments. Thus, one of homeopathy's most shining moments was tarnished, and even John Maddox was almost disappointed, concluding 'I'm sorry we didn't find something more interesting [13].'

The studies of the memory of water spurred Benveniste on to investigate how the molecules communicate within living cells. During all the stages of life the molecules have to talk to each other. In a transparent cell, containing one protein molecule to 10,000 water molecules, the molecules are jostling and pushing each other inside the cell. But if every molecule instead had its own signature frequency, its receptor or the molecule with matching spectrum of properties could tune to this frequency. They can tune in to the same resonance as each other - a body's vibration is amplified by another body's vibration at the same or almost the same frequency. This creates a cascade of electromagnetic impulses that travel at the speed of light, as Benveniste expressed it. (McTaggart 2001)

"Because science has long taught us to rely what we can see and touch, we often don't notice that our spirit, thoughts, emotions, and body are made of energy - that everything is vibrating. As we move out of the age of technology and into the age of intuition, we need tools to understand what it means to be a vibrational being and how natural frequency affects us". Penny Peirce in frequency the Power of Personal Vibration (Penny Peirce 2009)

\section{Discussion}

Cells are able to communicate with one another and help one another. Cells that are protected by amazing defences that protect us from intruders, sometimes it is a struggle between life-and-death. It is the hydrogen bonds in DNA's base pairs that constitute our immune system and all our consciousness, but consciousness, which is in the DNA's hydrogen bonds, can't see hear or feel. It congregates in the brain together with the senses and it is this seems strongly related to consciousness.

All over the world new science is discussed. Scientists like Nobel laureate Luc Montagnier, Jacques Beneviste $(1935$ - 2004) et. al. are rebuked but not to the same extent as Ignaz Semmelweis, $(1818-1865)$ their methods are not accepted by all.

"One of the foundations of homeopathy maintains that the potency of a substance is increased with its dilution. Montagnier discovered that solutions containing the DNA of viruses and bacteria "could emit low frequency radio waves" and that such waves influence molecules around them, turning them into organized structures. The molecules in turn emit waves and Montagnier found that the waves remain in the water even after it has been diluted many times. To a lay person, that may not mean much, but to a scientist is strongly suggests that homeopathy may have a scientific basis." [14].

The Semmelweis Reflex is the dismissing or rejecting out 
of hand any information, automatically, without thought, inspection, or experiment. The phrase stems from a number of people's personal experiences with the phenomenon, and denotes the reactions of anyone who engages in such behaviour.

Can life be reduced to nothing more than an interesting arrangement of atoms and molecules? Basic research team member Oyang Teng and 21st Century Science \& Technology editor Laurence Hecht discuss the implications of Luc Montagnier's recent experiments demonstrating water-mediated, low-frequency electromagnetic emission from bacterial and viral DNA. (Hecht, 2011) [15].

By demonstrating the interaction of living organisms with electromagnetic waves, perhaps including the low-frequency Schumann resonance waves in the Earth's atmosphere, the work has revolutionary implications for biology and our whole understanding of the universe extending the work begun in the 1920s by such figures as Alexander Gurwitsch, who detected ultraviolet radiations from growing plant cells. The Schumann resonance refers to the waves of base frequency $7.83 \mathrm{~Hz}$ and its higher harmonics which propagate in the waveguide formed between the surface of the Earth and the ionosphere. In 1952, German atmospheric physicist Winfried Schumann hypothesized that lightning activity would produce such low-frequency waves, and by dividing the circumference of the Earth by the velocity of light, he predicted the approximate frequency later detected. [16].

A remarkable feature of the results with bacteria and viruses is that many of the emitting filtrates are so highly diluted as to have almost no likelihood of containing the original infectious agent or its complete DNA. In order to account for this, as well as the appearance of signals from pure water, Montagnier adopted a hypothesis developed by researchers into the anomalous properties of water, namely, that coherent, polymeric nanostructures are formed in the water. A number of physical studies have reported the formation of long polymers of hydrogen-bonded dipoles in water.

The attempt to reduce the principle of life to something derivable from the laws of chemistry and physics was never very satisfactory. The argument of the vitalists, that an animating principle must be superimposed upon the presumably self-evident material substance of living matter, also had its limitations. With the results of Montagnier, we recognize that the principle, omne-vivum ex vivo, still holds, but only on the condition that we adopt a non-particle conception of life. (Hecht, 2011) [15].

Benviste's experiment showed that the cells don't rely on random collisions, but instead on electromagnetic signals with low frequency waves. Water is like a tape recorder that carries the information regardless whether the original molecule still exists or not. Water is so important for the transmission of energy and information, that Benviste's own studies shows that the molecular signals cannot be transmitted inside the body apart from through water [15]. Through a vast range of trials and experiments Benviste obtained evidence proving that the electromagnetic waves from living creatures affect the surroundings. The same result as the biophysicist Fritz-Albert Popp and predecessors had come to.

And not to mention the bio-resonance therapy that also is based on the memory of the water. Bio-resonance therapy is a holistic medicine technique that is based on the old learnings of acupuncture as well as biophysics and it originates from Germany. In Germany this method is used within the ordinary health service and has helped many people through the years to get rid of their allergies and stomach troubles etc. [16].

By simply using the allergen the patient's hypersensitivity can be "erased". The method of treatment was founded by the German biophysicist Fritz-Albert Popp, who has conducted research within cell communication. According to Popp one could clearly see that our cells are surrounded by electromagnetic vibration areas. He also came to the conclusion that the body communicates with the help of cell vibrations. Popp has proven that it is possible to steer biochemical processes in the cells by influencing their vibration areas. [17].

Robert O. Becker, M.D. is a pioneer in the field of regeneration and its relationship to electrical currents in living things, challenges the established mechanistic understanding of the body has written a book about the electromagnetism and the foundation of life. The Body Electric explores new pathways in our understanding of evolution, acupuncture, psychic phenomena, and healing (Becker 1985) [18].

He has also written a book, Cross Currents, about the perils of electro-pollution and the promise of electro-medicine (Becker 1990) [19].

Professor Becker is twice nominated for the Nobel Prize.

Consciousness is a phenomenon that cannot be explained inside the frame work for today's natural science [20].

\section{Conclusions}

My reflection: Water is a prerequisite for life to exist, and it may have some property necessary for it to tune in to the right frequency and carry the information forward. It is likely that life (in living cells) is a prerequisite for the water "to remember"

I think we will enter the nano-era where we can discover a whole new universe - which we wouldn't be able to see without an electron microscope.

Not only are our hearts powered by electrics, but actually so is every living cell. Maybe it is not so strange that the Nobel laureate Luc Montagnier found low frequency electromagnetic waves from bacterial DNA sequences.

Our bodies are consisting of 70 percent water and all body fluids contain water, water that is conductive and that is a solvent in which nourishment can be transported. Our 100 trillion cells contain two thirds worth of water. What is more natural than our immune system, our memory and our 
whole consciousness all operate and function with the help of water?

Perhaps life ends (or transfers into another dimension) when the electric current has run out within our cell?

\section{REFERENCES}

[1] Vitiello G. The use of many-body physics and thermodynamics to describe the dynamics of rhythmic generators in sensory cortices engaged in memory and learning. Current Opinion in Neurobiology 2015, 31:7-12.

[2] Enserink M. French Nobelist Escapes "Intellectual Terror" to Pursue Radical Ideas in China. Science 2010; 330, 6012:1732.

[3] Fredriksson, I. (Ed.) The Mysteries of Consciousness, Essays on Space time, evolution and Well-Being. North Carolina: McFarland \& Company; 2015.

[4] Chaplin M. Memory of Water. [cited 2015 Dec 12] Available from: http://www1.lsbu.ac.uk/water/memory_of_water.html.

[5] Nielsen RH. Livets vatten (Water of Life), Illustrerad Vetenskap (Science Illustrated).2007; 4 Available from: illvet.se/iv/livets-vatten. Swedish.

[6] Emoto M. Love Thyself: The Message from Water III. Hay House; 2006.

[7] Media Noetic org. [cited 2016 Jan 16]. Available from: http://media.noetic.org/uploads/files/Double-blind water.pdf

[8] Kaivararainen A. Unified Theory of Bivacuum, Particles Duality, Fields \& Time. New Bivacum Mediated Interaction, Overunity Devices, Cold Fusion Nucleosynthesis. 2002; [cited 2016 Jun 09] Available from: arxiv.org/pdf/physics/0207027

[9] Montagnier L, Aïssa J, Ferris S, Montagnier J-L, Lavallée C. Electromagnetic signals are produced by aqueous nanostructures derived from bacterial DNA sequences. Interdiscip. Sci. Comput. Life Sci. 2009; 81-90.

[10] Montagnier L, Aissa J, Del Giudice E, Lavallee C, Tedeschi
A, Vitiello G. DNA waves and water. Journal of Physics Conference Series306, 2011; 12007-16.

[11] Davenas E, Beauvais F, Amara J, Oberbaum M, Robinzon B, Miadonna AT, et al. Human basophil degranulation triggered by very dilute antiserum against IgE. Nature 1988; 333, 6176:816-18.

[12] Fortner P, Belon P, Sainte-Laudy J, Poitevin B, Benveniste J. When to believe the unbelievable. Nature 1988; 3336176:787-787.

[13] Langone J. The Water That Lost Its Memory. Time Magazine 1988; [cited 2016 Jun 09] Available from: http://content.time.com/time/magazine/article/0,9171,96808 0,00 .

[14] Nobel Prize Winner Prof Luc Montagnier Discovers Scientific Basis of Homeopathy [cited Jan 2016]. Available from: http://www.infiniteunknown.net/tag/luc-montagnier/

[15] The Coming Revolution in Wave Biology: An Interview with Dr. Luc Montagnier. http://archive.larouchepac.com/node/19 140

[16] Schumann. Electromagnetic models [cited 2016 May 15] Available from: http://www.paradigmshiftnow.net/human_e nergy_field/vo_hef_electromagnetic $\% 20$ models.htm

[17] Benveniste J. The molecular signal is not functioning in the absence of "informed" water. FASEB Journal, 1999; 1313:A163.

[18] Nienhaus J, Galle M. Internistisch-naturheil kundliche Praxis, Mulheim, Deutschland. CONCLUSION: The MORA bioresonance therapy can markedly improve non-organic gastrointestinal complaints. PMID: 16582548 [PubMed indexed for MEDLINE] ForschKomplementarmed. $2006 \mathrm{Feb}$; 13(1):28-34. Epub 2006 Jan 3.

[19] Prof. Fritz-Albert Popp. "We know today that man, essentially is a being of light" [cited 2016 May 15] Available from:

http://www.biontologyarizona.com/dr-fritz-albert-popp/

[20] Ernberg I, Blomberg C, Jörsäter S, Wennborg A, Århem P, Malmnäs P-E, et al. Vad är liv i kosmos, i cellen, i människan?(What is live?)Stockholm: Karolinska Institutet University Press; 2010. p.149 